\title{
A STUDY OF EFFICACY OF DEXMEDETOMIDINE AND MIDAZOLAM FOR SEDATION OF ECLAMPTIC PATIENTS ON MECHANICAL VENTILATION IN ICU
}

\author{
${ }_{1}^{1}$ Assistant Professor, Department of Anaesthesia, BRD Medical College, Gorakhpur. \\ ${ }^{2}$ Associate Professor, Department of Anaesthesia, BRD Medical College, Gorakhpur. \\ 3 Junior Resident, Department of Anaesthesia, BRD Medical College, Gorakhpur. \\ 4 Professor and HOD, Department of Anaesthesia, BRD Medical College, Gorakhpur. \\ ${ }_{5}^{5}$ Assistant Professor, Department of Anaesthesia, BRD Medical College, Gorakhpur. \\ ${ }^{6}$ Assistant Professor, Department of Anaesthesia, BRD Medical College, Gorakhpur. \\ 7 Professor, Department of Anaesthesia, BRD Medical College, Gorakhpur.
}

Santosh Kumar Sharma1, Shahbaz Ahmad², Zulutena Jamir ${ }^{3}$, Satish Kumar ${ }^{4}$, Priyanka Dwivedi ${ }^{5}$, Narendra Deo $^{6}$, Raka Rani $^{7}$

\section{ABSTRACT}

\section{BACKGROUND}

It remains a challenge to provide optimal sedation for eclamptic patients on mechanical ventilation in ICU, who are often irritable. Traditionally, Midazolam, a fast-acting benzodiazepine, has been the most commonly administered sedative drug for ICU patients worldwide. Dexmedetomidine, a highly selective $\alpha_{2}$-adrenergic receptor agonist, is a newer sedative used for ICU sedation having better haemodynamic stability and no respiratory depressant effect.

Aim- To compare efficacy of dexmedetomidine and midazolam for sedation of eclamptic patients on mechanical ventilation in ICU.

\section{MATERIALS AND METHODS}

In a prospective study, 100 eclamptic patients aged more than 18 years who required mechanical ventilation in intensive care unit (ICU) after lower segment caesarean section (LSCS) were divided equally into two groups to receive either midazolam (Group I) or dexmedetomidine (Group II). Vital parameters, level of sedation (Ramsay sedation Score 1-6), any side effects were observed and compared.

\section{RESULTS}

Both groups showed decrease in heart rate (HR) and blood pressure (SBP, DBP, MAP) at all-time intervals, but the decrease was statistically significant $(p<0.005)$ in Group II at most time intervals. Both the groups maintained predominantly stable haemodynamics at all times. The Ramsay Sedation Score was also comparable and it maintained at a mean score of 2-3 at most time intervals in both groups. The incidence of bradycardia and hypotension was significantly higher in group II as compared to group I.

\section{CONCLUSION}

Dexmedetomidine provided an effective alternative to midazolam in producing and maintaining controlled (RSS 2-3) short-term sedation in mechanically ventilated eclampsia patients and stable haemodynamics.

\section{KEYWORDS}

ICU Sedation, Dexmedetomidine, Midazolam, Eclampsia.

HOW TO CITE THIS ARTICLE: Sharma SK, Ahmad S, Jamir Z, et al. A study of efficacy of dexmedetomidine and midazolam for sedation of eclamptic patients on mechanical ventilation in ICU. J. Evolution Med. Dent. Sci. 2017;6(30):2415-2418, DOI: 10.14260/Jemds/2017/521

\section{BACKGROUND}

Preeclampsia is a multisystem, hypertensive disorder which complicates up to $8 \%$ pregnancies,(1) out of which around $25 \%$ advance into eclampsia. Eclamptic patients often land up in Intensive Care Unit (ICU) due to complications or for further postoperative care and frequently need mechanical ventilation. Mechanical ventilation is often associated with patient agitation and reduced tolerance hence requiring sedation to alleviate discomfort and improve patientventilator synchrony,(2) and also to facilitate nursing care and improve outcome. It is quite a challenge for optimum care of

Financial or Other, Competing Interest: None.

Submission 07-03-2017, Peer Review 01-04-2017,

Acceptance 06-04-2017, Published 13-04-2017.

Corresponding Author:

Dr. Santosh Kumar Sharma,

Type 4/3, BRD Medical College Campus,

Gorakhpur-273013.

E-mail: santoshtata76@gmail.com

DOI: $10.14260 /$ jemds $/ 2017 / 521$ eclamptic patients in ICU who are usually irritable. Various agents are being used for ICU sedation, such as propofol, midazolam, fentanyl and lately dexmedetomidine. Traditionally, Midazolam has been the most commonly administered sedative drug for ICU patients worldwide.(3) Midazolam is a fast-acting benzodiazepine that rapidly penetrates the central nervous system to produce an onset of sedation in 2 to 2.5 minutes.(4) All benzodiazepines reliably cause amnesia, but have no analgesic activity (hence often combined with fentanyl), and produce dose-dependent respiratory depression which is enhanced in combination with opioids. Hence, long-term or high dosage of midazolam in the critically ill patients may lead to oversedation; prolonged mechanical ventilation and longer ICU stay. Dexmedetomidine is a newer sedative used for ICU sedation and has better haemodynamic stability and minimal respiratory depressant effect.(5) Dexmedetomidine is a highly selective $\alpha_{2}$-adrenergic receptor agonist. In contrast to other sedative hypnotic agents, dexmedetomidine also has adequate analgesic effect and may induce a sedative state 
similar to physiologic sleep by acting on $\alpha_{2}$ receptors in the locus coeruleus.(6) Various studies regarding the efficacy of midazolam and dexmedetomidine for sedation of critically ill patients in ICU have been done globally. $(3,7)$ The studies comparing efficacy of midazolam and dexmedetomidine for sedation in eclamptic patients requiring mechanical ventilation in ICU are minimal.(7)

The aim of this clinical study was to compare the efficacy of dexmedetomidine and midazolam for sedation of eclamptic patients on mechanical ventilation in ICU so that a near ideal sedative agent for eclamptic patients could be determined

\section{MATERIALS AND METHODS}

The present prospective study comprising of 100 eclamptic pregnant women more than 18 years of age undergoing Lower Segment Caesarean Section for termination of pregnancy under general anaesthesia and requiring postoperative mechanical ventilation in ICU at Nehru Hospital, BRD medical college, Gorakhpur was planned. The study period was of one year from September 2014 to August 2015. After the approval of the institutional ethical committee, an informed written consent was taken from all patients' first degree relatives. 100 postoperative patients (LSCS for termination of pregnancy under GA) were selected and distributed randomly into two groups of 50 each (By paper chits prepared in a box) who were sedated either by IV midazolam or dexmedetomidine immediately after admission in the ICU.

The exclusion criteria were patients with baseline $\mathrm{HR}<60$ $\mathrm{bpm}$, those with hypovolaemia and SBP $<90 \mathrm{~mm}$ of $\mathrm{Hg}$, those with Mobitz type 2 and $3^{\text {rd }}$ degree heart block, those with preexisting comorbidities like cardiac, hepatic, pulmonary, neurological, endocrine or renal diseases, patients with past history of chronic hypertension, those developing Haemolysis, Elevated Liver enzymes and low platelets (HELLP syndrome), having allergy to the study drugs, history of drug abuse, use of antipsychotic or sedative medications. Group I received loading dose of $0.05 \mathrm{mg} / \mathrm{kg}$ of midazolam over 10 minutes followed by maintenance dose of 0.1 $\mathrm{mg} / \mathrm{kg} /$ hour $(50 \mathrm{mg}$ of midazolam made to $50 \mathrm{~mL}$ with $0.9 \%$ $\mathrm{NaCl}$ and connected to syringe infusion pump was used). Group II received loading dose of $1 \mu \mathrm{g} / \mathrm{kg}$ of dexmedetomidine over 10 minutes followed by maintenance dose of $0.5 \mu \mathrm{g} / \mathrm{kg} / \mathrm{hour}$ ( $200 \mu \mathrm{g}$ of dexmedetomidine made to $50 \mathrm{~mL}$ with $0.9 \% \mathrm{NaCl}$ and connected to syringe infusion pump was used). The drug combinations were prepared by an anaesthesiologist not involved in patient monitoring and followup. Vital parameters - Invasive blood pressure (IBP), oxygen saturation $\left(\mathrm{SpO}_{2}\right)$, heart rate $(\mathrm{HR})$ and electrocardiography (ECG) of all patients were monitored in the ICU. All patients received $\mathrm{MgSO}_{4} 2 \mathrm{~g}$ every $4^{\text {th }}$ hourly for 24 hours and rest of the treatment was as per our standard ICU protocol. The Ramsay Sedation Score was assessed hourly with target sedation of 2-3. Visual analogue scale (VAS 0 - 10) was assessed hourly and every patient received injection fentanyl IV $1 \mu \mathrm{g} / \mathrm{kg}$ if VAS $>4$. Patients with mean arterial pressure (MAP) $>130 \mathrm{mmHg}$ were administered Inj. Labetalol $20 \mathrm{mg}$ bolus as antihypertensive and if response was inadequate it was repeated as per guidelines. Patients were continuously observed for any episode of convulsion and were treated with injection thiopentone. Side effects like hypotension if systolic blood pressure (SBP<90 $\mathrm{mmHg}$ ), hypertension if mean arterial pressure (MAP $>130 \mathrm{mmHg}$ ), tachycardia if $\mathrm{HR}>100 \mathrm{bpm}$, bradycardia if $\mathrm{HR}<60 \mathrm{bpm}$ and level 4 sedation were observed and treated in both groups. All parameters and observations were recorded by two anaesthesiologists on rotation basis not involved in preparation of the study drugs. The mode of mechanical ventilation was synchronised intermittent mandatory ventilation (SIMV) and pressure support (PS) in all patients and gradual weaning and extubation was done as per our standard ICU guidelines.

\section{Statistical Analysis}

The sample size was calculated considering power of test as $80 \%$, confidence interval of $95 \%$, ratio of sample size (between group II and group I) as one. For this study, it was expected that the difference observed in mean between two groups was ten. SPSS version 21 was used to perform statistical analysis. The data were expressed in mean \pm standard deviation (Range). Statistical analysis was done using student $t$ test, paired for intragroup and unpaired for intergroup comparisons. A value of $p<0.05$ was considered to be statistically significant while $p<0.001$ was considered highly statistically significant.

\section{RESULTS}

Hundred patients were enrolled in the study and all completed the study. The demographic data in both the groups were statistically insignificant (Table 1). The difference in mean Ramsay Sedation Scores were statistically insignificant in both groups from $2^{\text {nd }}$ to 24 hours. Haemodynamically, there was decrease in pulse rate in both the groups at all-time intervals and this decrease was significant in group II at $8^{\text {th }}, 12^{\text {th }}$, and $24^{\text {th }}$ hour ( $\mathrm{p}$ value 0.002) in comparison to group I (Table 3). The drop in mean systolic blood pressure (and mean arterial blood pressure) was statistically significant in group II at $1^{\text {st }}$ hour ( $\mathrm{p}$ value 0.0041 ) and remained highly significant at $2^{\text {nd }}$ to $24^{\text {th }}$ hour ( $p$ value $<0.0001$ ) (Table 4 and table 6 respectively). Similarly, the drop in mean diastolic blood pressure in group II was significant at $1^{\text {st }}$ and $2^{\text {nd }}$ hour and it became highly significant ( $p$ value $<0.0001$ ) from $4^{\text {th }}$ to $24^{\text {th }}$ hour (Table 5). There were 10 patients each of bradycardia and hypotension in group II.

\begin{tabular}{|c|c|c|}
\hline \multicolumn{3}{|c|}{ No. of Patients 50 each } \\
\hline & Group I & Group II \\
\hline Mean Age (Years) & $20.90 \pm 2.06$ & $20.94 \pm 2.12$ \\
\hline Weight (Kg) & $52.08 \pm 3.96$ & $53.60 \pm 2.88$ \\
\hline Height (cm) & $160.12 \pm 3.54$ & $162.24 \pm 2.62$ \\
\hline
\end{tabular}

Table 1. Showing Patient Characteristics in Both Groups

\begin{tabular}{|c|c|c|c|c|}
\hline Time & Group I & Group II & t' Value $^{\text {p' Value }}$ \\
\hline Pre-drug & $1 \pm 0$ & $1 \pm 0$ & & \\
\hline $1 \mathrm{hr}$. & $1.98 \pm 0.31$ & $2.26 \pm 0.43$ & 3.73 & $0.0003^{* *}$ \\
\hline $2 \mathrm{hr}$. & $2.16 \pm 0.36$ & $2.2 \pm 0.40$ & 0.52 & 0.60 \\
\hline $4 \mathrm{hr}$. & $2.18 \pm 0.38$ & $2.24 \pm 0.42$ & 0.74 & 0.45 \\
\hline $8 \mathrm{hr}$. & $2.48 \pm 0.49$ & $2.52 \pm 0.49$ & 0.40 & 0.68 \\
\hline $12 \mathrm{hr}$. & $2.6 \pm 0.49$ & $2.64 \pm 0.48$ & 0.41 & 0.67 \\
\hline $24 \mathrm{hr}$. & $2.08 \pm 0.27$ & $2.18 \pm 0.38$ & 1.51 & 0.1 \\
\hline \multicolumn{5}{|c|}{ Table 2. Comparison of Ramsay } \\
Sedation Score in Both Groups \\
\hline
\end{tabular}

$\mathrm{p}>0.05$ = insignificant, $\mathrm{p}<0.05=$ significant ${ }^{*}, \mathrm{p}<0.001=$ highly significant $* *$ 


\begin{tabular}{|c|c|c|c|c|}
\hline Time & Mean PR/minute & $\begin{array}{c}\mathbf{t} \\
\text { Value }\end{array}$ & $\begin{array}{c}\text { p } \\
\text { Value }\end{array}$ \\
\hline & Group I & Group II & & \\
\hline Pre-drug & $118.69 \pm 14.36$ & $121.02 \pm 22.02$ & 0.62 & 0.532 \\
\hline $1 \mathrm{hr}$. & $111.65 \pm 15.40$ & $110.89 \pm 17.84$ & 0.22 & 0.821 \\
\hline $2 \mathrm{hr}$. & $106.21 \pm 15.41$ & $101.55 \pm 18.23$ & 1.38 & 0.17 \\
\hline $4 \mathrm{hr}$. & $101.38 \pm 14.73$ & $95.11 \pm 19.61$ & 1.80 & 0.073 \\
\hline $8 \mathrm{hr}$. & $95.49 \pm 16.49$ & $84.44 \pm 19.53$ & 3.05 & $0.002^{*}$ \\
\hline $12 \mathrm{hr}$. & $90.45 \pm 15.67$ & $78.79 \pm 14.69$ & 3.83 & $0.002^{*}$ \\
\hline $24 \mathrm{hr}$. & $89.21 \pm 14.20$ & $77.15 \pm 12.05$ & 4.57 & $<0.0001^{* *}$ \\
\hline \multicolumn{5}{|c|}{ Table 3. Statistical Analysis of Mean } \\
\hline
\end{tabular}

$\mathrm{p}>0.05$ = insignificant, $\mathrm{p}<0.05=$ significant*, $\mathrm{p}<0.001=$ highly significant $* *$

\begin{tabular}{|c|c|c|c|c|}
\hline Time & \multicolumn{2}{|c|}{$\begin{array}{c}\text { Mean } \\
\text { SBP }\end{array}$} & $\begin{array}{c}\text { t } \\
\text { Value }\end{array}$ & $\begin{array}{c}\text { p } \\
\text { Value }\end{array}$ \\
\hline & Group I & Group II & & \\
\hline Pre-drug & $151.57 \pm 18.10$ & $147.76 \pm 16.83$ & 1.08 & 0.278 \\
\hline $1 \mathrm{hr}$. & $144.76 \pm 18.96$ & $134.32 \pm 16.47$ & 2.93 & $0.0041^{*}$ \\
\hline $2 \mathrm{hr}$. & $140.50 \pm 17.98$ & $123.30 \pm 18.58$ & 4.70 & $<0.0001^{* *}$ \\
\hline $4 \mathrm{hr}$. & $137.19 \pm 18.55$ & $111.31 \pm 15.91$ & 7.48 & $<0.0001^{* *}$ \\
\hline $8 \mathrm{hr}$. & $130.68 \pm 23.98$ & $109.05 \pm 15.48$ & 5.35 & $<0.0001^{* *}$ \\
\hline $12 \mathrm{hr}$. & $129.14 \pm 16.19$ & $109.22 \pm 12.69$ & 6.84 & $<0.0001^{* *}$ \\
\hline $24 \mathrm{hr}$. & $127.48 \pm 20.94$ & $109.58 \pm 11.07$ & 5.34 & $<0.0001^{* *}$ \\
\hline
\end{tabular}

Table 4. Comparison of Mean SBP in Both Groups

$\mathrm{p}>0.05=$ insignificant, $\mathrm{p}<0.05=$ significant ${ }^{*} \mathrm{p}<0.001=$ highly significant $* *$

\begin{tabular}{|c|c|c|c|c|}
\hline Time & \multicolumn{2}{|c|}{ Mean DBP } & $\begin{array}{c}\mathbf{t}^{\prime} \\
\text { Value }\end{array}$ & $\begin{array}{c}\mathbf{p}^{\prime} \\
\text { Value }\end{array}$ \\
\hline & Group I & Group II & 0.87 & 0.3851 \\
\hline Pre-drug & $93.80 \pm 12.07$ & $91.72 \pm 11.81$ & $0.0147^{*}$ \\
\hline $1 \mathrm{hr}$. & $90.16 \pm 14.41$ & $83.89 \pm 10.53$ & 2.48 & 0.0019 \\
\hline $2 \mathrm{hr}$. & $85.50 \pm 12.50$ & $77.68 \pm 11.94$ & 3.19 & $0.0019^{*}$ \\
\hline $4 \mathrm{hr}$. & $83.54 \pm 13.34$ & $74.06 \pm 12.11$ & 3.72 & $0.0003^{*}$ \\
\hline $8 \mathrm{hr}$. & $85.80 \pm 13.99$ & $74.94 \pm 13.09$ & 4.26 & $<0.0001^{* *}$ \\
\hline $12 \mathrm{hr}$. & $82.94 \pm 10.24$ & $72.19 \pm 9.71$ & 5.38 & $<0.0001^{* *}$ \\
\hline $24 \mathrm{hr}$. & $82.85 \pm 11.37$ & $71.60 \pm 9.98$ & 5.25 & $<0.0001^{* *}$ \\
\hline
\end{tabular}

Table 5. Comparison of Mean DBP in Both Groups

$\mathrm{p}>0.05$ = insignificant, $\mathrm{p}<0.05=$ significant ${ }^{*}, \mathrm{p}<0.001=$ highly significant $* *$

\begin{tabular}{|c|c|c|c|c|}
\hline Time & \multicolumn{2}{|c|}{ Mean MAP } & t' Value & p' Value \\
\hline & Group I & Group II & & \\
\hline Pre-drug & $114.91 \pm 12.29$ & $111.60 \pm 10.59$ & 1.44 & 0.152 \\
\hline $1 \mathrm{hr}$. & $110.87 \pm 14.45$ & $102.40 \pm 10.71$ & 3.32 & 0.0012 \\
\hline $2 \mathrm{hr}$. & $106.23 \pm 11.03$ & $94.19 \pm 12.15$ & 5.18 & $<0.0001^{* *}$ \\
\hline $4 \mathrm{hr}$. & $104.92 \pm 12.45$ & $88.34 \pm 11.79$ & 6.83 & $<0.0001^{* *}$ \\
\hline $8 \mathrm{hr}$. & $102.41 \pm 14.21$ & $88.16 \pm 13.36$ & 5.16 & $<0.0001^{* *}$ \\
\hline $12 \mathrm{hr}$. & $101.40 \pm 11.81$ & $86.60 \pm 9.36$ & 6.94 & $<0.0001^{* *}$ \\
\hline $24 \mathrm{hr}$. & $100.37 \pm 9.60$ & $87.52 \pm 14.76$ & 5.16 & $<0.0001^{* *}$ \\
\hline \multicolumn{5}{|c|}{ Table 6. Comparison of Mean MAP in Both Groups } \\
\hline
\end{tabular}

p $>0.05=$ insignificant, $p<0.05=$ significant ${ }^{*}, p<0.001=$ highly significant $* *$

\begin{tabular}{|c|c|c|}
\hline Side-Effects & Group I & Group II \\
\hline Bradycardia & 1 & 10 \\
\hline Hypotension & 0 & 10 \\
\hline Level 4 sedation & 0 & 0 \\
\hline \multicolumn{2}{|r|}{ Table 7. Table Showing Side- } \\
effects among Two Drugs used \\
\hline
\end{tabular}

\section{DISCUSSION}

The eclamptic patients often need to be mechanically ventilated in the ICU postoperatively after LSCS. Sedation in ICU is of paramount importance in such patients. The goals and standards for analgesia cum sedation of mechanically ventilated ICU patients have undergone considerable changes in the past few years. While excessively deep levels of sedation resulted in increased morbidity due to prolongation of mechanical ventilation and ICU stay, on the other hand inadequate sedation increased the risk of accidental extubation and other adverse events. The goal of sedation in ICU in present scenario is to have a calm, but arousable patient, with stable haemodynamics. Midazolam continues to be the most commonly administered sedative drug for ICU patients worldwide, including our hospital. On the other hand, dexmedetomidine is a newer, effective and safe sedative agent finding its way into the ICU.

In our study, the study groups were comparable in all patient characteristics (Table 1). On comparison of Ramsay Sedation Score, both Group I and group II had mean Ramsay Sedation Score of $1 \pm 0$ before starting the study drug and was maintained at a mean score of 2 at most times in both groups. On statistical evaluation, it was found that the $p$ value was highly significant at $1^{\text {st }}$ hour but by $2^{\text {nd }}$ to $24^{\text {th }}$ hour it was not significant ( $p$ value $>0.05$ ), meaning that both group I and group II are comparable in sedation levels (Table 2).

Riker et al (2009), Jacob et al (2012), Adams et al (2013), S. Gupta et al (2015) observed no statistically significant difference between dexmedetomidine and midazolam regarding levels of sedation with the two study drugs. $(3,8,9,10)$

The pulse rate decreased in both the groups at all-time intervals and this decrease in group II at $8^{\text {th }}, 12^{\text {th }}$, and $24^{\text {th }}$ hour was significant (p value 0.002 ) in comparison to group I (Table 3). Esmaoglu et al (2009) observed that dexmedetomidine markedly reduced the heart rates in the first 24 hours $(\mathrm{P}<0.05)$ compared to midazolam.(7) S Gupta, et al (2015) observed that the fall in heart rate in dexmedetomidine group was not significant in first 15 hours but by $16^{\text {th }}$ hour it became significant till $24^{\text {th }}$ hour. They had observed a $28 \%$ reduction in pulse rate from the baseline in dexmedetomidine group whereas $7 \%$ reduction was seen in midazolam group. In our study, we observed $29.48 \%$ reduction in pulse rate in group I and $43.87 \%$ reduction in group II.(10) This could be due to the fact that our patients were eclamptic and hence high intracranial tension (ICT) lead to accentuated decrease in heart rate. There was decrease in mean systolic blood pressure in both the two groups, but it was more pronounced in group II and was statistically significant at $1^{\text {st }}$ hour ( $p$ value 0.0041 ) and remained highly significant at $2^{\text {nd }}$ to $24^{\text {th }}$ hour (p value $<0.0001$ ) (Table 4 ). There was a decrease in mean diastolic blood pressure in both groups but more decrease was seen in group II and was significant at $1^{\text {st }}$ and $2^{\text {nd }}$ hour but by $4^{\text {th }}$ to $24^{\text {th }}$ hour it became highly significant ( $p$ value $<0.0001$ ) (Table 5). There was reduction in mean arterial blood pressure in both groups but more decrease in blood pressure was seen in group II. And the decrease in MAP was significant in $1^{\text {st }}$ hour ( $p$ value 0.0012 ) and remained highly significant by $2^{\text {nd }}$ to $24^{\text {th }}$ hour ( $p$ value $<0.0001$ ) (Table 6). Venn et al (1999) observed that 18 of the 66 patients receiving dexmedetomidine experienced significant hypotension (Mean arterial pressure $<60 \mathrm{mmHg}$ or $>30 \%$ fall from pre-infusion values).(11) A randomised 
controlled trial by Jakob et al in 2012 observed that dexmedetomidine group had more decrease in blood pressure (26\%) as compared to midazolam group (11.6\%).(8)

Comparing the side-effects of the two drugs administered, it was observed that 1 patient (2\%) in group I had arrhythmic events while group II had none. Bradycardia $(\mathrm{HR}<60)$ was observed in 1 patient (2\%) in group I whereas group II had 10 patients experiencing bradycardia (20\%). Finally, hypotension (Systolic BP $<90 \mathrm{mmHg}$ ) was not noted in group I, but was observed in 10 patients (20\%) among group II patients (Table 7).

A study by Riker et al (2009) observed that dexmedetomidine treated patients were more likely to develop bradycardia i.e. $42.2 \%$ versus $18.8 \%$ as compared to midazolam.(3)

Similar results were observed by Prasad et al (2012) who compared dexmedetomidine with fentanyl for postoperative sedation in cardiac surgical patients and observed that the frequency of bradycardia in dexmedetomidine group was significantly higher.(12)

A meta-analysis by Jen A. Tan et al observed that dexmedetomidine was associated with increased risk of bradycardia and hypotension.(6)

It was observed that 3 patients (6\%) in group I needed antihypertensive drug (IV labetalol) while it was not required in group II. Esmaoglu et al in 2009 observed that in patients who were given dexmedetomidine only few required nitroglycerin and nitroprusside as compared to midazolam.(7)

It was observed that 1 patient $(2 \%)$ of group II had convulsion episode whereas it was not observed among group I patients.

Comparing the ICU stay in hours in both group I and group II, it was observed that group I had mean duration of 39 hours whereas that of group II was 38.48 hours and were almost comparable.

Also a study by Stephen M Jacob et al (2012) observed that length of ICU stay was similar in both dexmedetomidine and midazolam groups. ${ }^{(8)}$

In this study, we found that dexmedetomidine is as effective as midazolam for producing and maintaining adequate short-term sedation of mechanically ventilated eclampsia patients and also has good haemodynamic control.

\section{Limitations of the Study \\ The study included a small number of participants. Secondly, there was use of magnesium sulfate liberally in the study patients which can also cause sedation along with hypotension. Thirdly, only mean duration of ICU stay was observed but extubation time was not included in the study.}

\section{CONCLUSION}

In this study, we found that dexmedetomidine is as effective as midazolam for producing and maintaining adequate shortterm sedation of mechanically ventilated eclampsia patients and also has good haemodynamic control. The risk of bradycardia and hypotension although higher than traditional sedatives, it may not increase length of hospital stay. Thus, dexmedetomidine could be a safe and efficacious sedative agent in eclamptic patients in ICU.

\section{REFERENCES}

[1] World Health Organization International Collaborative Study of Hypertensive Disorders in Pregnancy. Geographic variation in the incidence of hypertension in pregnancy. Am J Obstet Gynecol 1988;158(1):80-3.

[2] Rotondi AJ, Chelluri L, Sirio C, et al. Patients' recollections of stressful experiences while receiving prolonged mechanical ventilation in an intensive care unit. Crit Care Med 2002;30(4):746-52.

[3] Riker RR, Shehabi Y, Bokesch PM, et al. Dexmedetomidine versus midazolam for sedation of critically ill patients-a randomized trial. JAMA 2009;301(5):489-99.

[4] Shapiro BA, Warren J, Egol AB, et al. Practice parameters for intravenous analgesia and sedation for adult patients in the intensive care unit: an executive summary. Crit Care Med 1995;23(9):1596-600.

[5] Bindu B, Pasupuleti S, Reddy B, et al. Dexmedetomidine: a review. J Sci Res Phar 2012;1(3):1-6.

[6] Tan JA, Ho KM. Use of dexmedetomidine as a sedative and analgesic agent in critically ill adult patients: a meta-analysis. Intensive Care Med 2010;36(6):926-39.

[7] Esmaoglu A, Ulgey A, Akin A, et al. Comparison between dexmedetomidine and midazolam for sedation of eclamptic patients in the intensive care unit. J Crit Care 2009;24(4):551-5.

[8] Jakob SM, Ruokonen E, Grounds RM, et al. Dexmedetomidine versus midazolam or propofol for sedation during prolonged mechanical ventilation: two randomized controlled trials. JAMA 2012;307(11):1151-60.

[9] Adams R, Brown GT, Davidson M, et al. Efficacy of dexmedetomidine compared with midazolam for sedation in adult intensive care patients: a systemic review. BJA 2013;111(5):703-10.

[10] Gupta S, Singh D, Sood D, et al. Role of dexmedetomidine in early extubation in the intensive care unit patients. J Anaesthesiol Clin Pharmacol 2015;31(1):92-8.

[11] Venn RM, Bradshaw CJ, Spencer R, et al. Preliminary UK experience of dexmedetomidine, a novel agent for postoperative sedation in the intensive care unit. Anaesthesia 1999;54(12):1136-42.

[12] Prasad SR, Simha PP, Jagadeesh AM. Comparative study between dexmedetomidine and fentanyl for sedation during mechanical ventilation in postoperative pediatric cardiac surgical patients. Indian J Anaesth 2012;56(6):547-52. 